\title{
KOMITMEN ORGANISASI \\ STUDI KAUSAL MOTIVASI BERPRESTASI DAN KEPUASAN KERJA \\ TERHADAP KOMITMEN ORGANISASI DOSEN DI UNIVERSITAS MUHAMMADIYAH (UMMI) KOTA SUKABUMI
}

\author{
Muhammad Ichsan*
}

\begin{abstract}
This study aims to solve existing problems at the University The problem that occurs is thought to still lower organizational commitment lecturer at the University of Muhammadiyah Sukabumi caused by the low achievement motivation factors and job satisfaction among faculty. Therefore, the causal approach and method of the survey are expected to increase the degree of organizational commitment of the lecturers at the University of Muhammadiyah Sukabumi. This research was conducted diUniversitas Muhammadiyah Sukabumi for three months, from May 2010 until July 2010. The research concludes the research hypothesis is accepted and implies: (1) there is a significant direct effect on organizational commitment, achievement motivation, (2) the existence of a significant direct effect of job satisfaction lecturer on organizational commitment, (3) there is a significant direct effect on achievement motivation job satisfaction; increase in the degree of organizational commitment and positive impact on university lecturers.
\end{abstract}

Keywords: achievement motivation, job satisfaction, organizational commitment.

\section{PENDAHULUAN}

Peningkatan kualitas pendidikan pada perguruan tinggi akan dicapai, bila perguruan tinggi melakukan pengembangan akademik secara terus-menerus. Peningkatan akademik akan meningkatkan daya saing atau keunggulan kompetitif. Keunggulan kompetitif perguruan tinggi dapat didilakukan melalui optimalisasi aspek sinergitas. Dodi Nandika dalam Syahrizal Abbas (2008:146) menyebutkan bahwa aspek sinergi menjadi kata kunci dalam peningkatan daya saing perguruan tinggi. Setiap perguruan tinggi memiliki potensi dan permasalahannya dalam mensinergikan semua komponen sumber daya organisasinya, tak terkecuali Universitas Muhammadiyah Sukabumi. Universitas tersebut diresmikan bulan Juni 2002 dan mendapat izin operasional Dirjen Dikti No. 81/D/0/2003 tertanggal 13 Juni 2003. UMMI merupakan kampus pertama di Kota Sukabumi yang representatif dan berskala besar serta memiliki potensi dan permasalahan yang menarik untuk diteliti. Penulis ingin mengetahui apakah ada pengaruh langsung yang signifikan dari variabel motivasi berprestasi dan variabel kepuasan kerja dosen terhadap variabel komitmen organisasi. Berkaitan dengan komitmen organisasi dalam dunia perguruan tinggi, komitmen seorang dosen terhadap organisasinya menjadi isu yang sangat strategis, karena dosen yang memiliki komitmen tinggi akan memberikan dedikasi dan loyalitasnya terhadap perguruan tinggi tersebut. Dengan demikian, organisasi dapat berjalan dengan baik sesuai visi dan misi serta tujuan yang akan dicapai. Bahkan begitu pentingnya aspek komitmen organisasi, tidak sedikit dari perguruan tinggi yang menjadikan syarat dalam pengembangan karier dosennya. Penelitian terhadap komitmen organisasi menjadi penting dalam organisasi atau institusi perguruan tinggi karena diyakini bahwa komitmen yang tinggi akan mendorong peningkatan pemberdayaan organisasi yang

\footnotetext{
* Dosen Universitas Muhammadiyah Kota Sukabumi
} 
pada gilirannya akan meningkatkan efektivitas dan produktivitas. Hal tersebut menjadi perhatian yang serius dari para manager institusi perguruan tinggi, agar kelangsungan hidup organisasi yang bersangkutan menjadi terjamin. Motivasi dan kepuasan kerja yang rendah menimbulkan berbagai dampak negatif seperti mangkir kerja, pindah kerja, malas bekerja, dan sebagainya. Hal tersebut berakibat cukup serius bagi organisasi walaupun manifestasi kerugiannya cenderung jangka panjang.

Dosen dan karyawan tidak hanya mengharapkan imbalan atas jasa yang diberikannya kepada tempatnya bekerja, tetapi juga mengharapkan kualitas tertentu dari perlakuan tempat kerjanya. Hal yang wajar bila seorang dosen mendambakan penghargaan dari kebijakan yang mempengaruhi kerja dan karier mereka, menginginkan rekan sekerja yang kooperatif, serta kompensasi yang adil dan memadai. Tuntutan kerja yang tinggi disertai respon positif oleh organisasi akan menentukan derajat komitmen dosen dan pegawai terhadap organisasi, yang pada akhirnya mempengaruhi keputusan mereka untuk tetap bergabung dan memajukan organisasinya atau memilih tempat kerja lain yang lebih jelas statusnya dan lebih menjanjikan kesejahteraannya. Dengan demikian, dari uraian di atas, penulis ingin mengembangkan penelitian terhadap komitmen organisasi yang diduga dipengaruhi oleh motivasi berprestasi dan kepuasan kerja dosen.

\section{Komitmen organisasi.}

Walker (1992:87) mendefinisikan komitmen dengan "commitment is the willingnes of people to stay with the organization and contribute energitically to achievement of share objective." (komitmen adalah keinginan seseorang untuk tetap berada dalam organisasi dan berkontribusi secara energik untuk bersama-sama mencapai keberhasilan). Lebih lanjut Colquitt, Lepine, dan Wesson mengutip Mowday (2009:67) menegaskan bahwa komitmen organisasi adalah as the desire on the part of an employee to remain a member of the organization. Sedangkan J. P. Meyer, N. J. Alen, and C. A. Smith sebagai mana dikutip Stephen P. Robbin dan Timothy A. Judge (2009:111) mendefinisikan organizational commitment the degree to witch a particular organization and its goals and whises to maintain membership in the organization. Komitmen organisasi berarti derajat dukungan pegawai dalam melaksanakan tujuan organisasi dan kesadaran untuk tetap berada di dalam organisasi. Dalam kaitannya dengan model komitmen, Hersey (1996:446) membaginya ke dalam lima model, yaitu: Pertama, komitmen terhadap pelanggan (commitment to the customer), Kedua, komitmen kepada organisasi (commitment to the organization), ketiga, komitmen kepada diri (commitment to self), keempat, Komitmen kepada orang-orang (comitmen to people), dan kelima, komitmen kepada tugas (commitment to task). Komitmen pada organisasi dapat diartikan komitmen terhadap tujuan, nilai, dan sasaran organisasi.

Untuk menunjukan secara lengkap kriteria mengukur adanya derajat komitmen, Marcia (1993:208-210) menjelaskannya sebagai berikut: Pertama, knowledge ability, yaitu kemampuan mengetahui berbagai jenis pekerjaan yang telah ia pilih sesuai keputusan awal dirinya. Pegawai yang berkomitmen dapat diketahui dari apa yang ia dapatkan sesuai target dan sasaran, maka perilakunya akan konsisten sesuai dengan komitmennya. Misalnya, seorang pegawai tidak begitu saja dipercaya bahwa ia telah berkomitmen terhadap profesinya, jika pengetahuannya tentang spesialisasi dan keahliannya minim dan ia tidak berusaha untuk meningkatkan ilmu pengetahuannya. Kedua, aktivity directed toward implementing the chosen identity elements, yaitu kegiatan terarah mengimplementasikan keputusan awal tentang pekerjaan yang telah dipilih. Untuk mendapatkan sesuatu, pegawai tidak hanya cukup memikirkannya tetapi ia 
harus mencari pengalaman-pengalaman yang relevan. Komitmen menghendaki keterlibatan perilaku dengan apa yang ia janjikan. Ketiga, emotional tone, yaitu keterlibatan emosional. Secara esensial emosi atau afeksi bagi status-status identitas adalah sebagai berikut: a) Status achievement cenderung memiliki keyakinan diri yang solid, puas dengan dirinya sendiri. b) Status Foreclosur cenderung memiliki kebenaran diri (self righteousness) yang tidak fleksibel. c) Status Moratorium memiliki semangat juang, intensitas, kadang-kadang cemas dan tidak realistis dalam bertindak. d) Status Diffusion memiliki emosi sedih, terisolasi, atau sebaliknya memiliki kegembiraan yang berpindah-pindah. Secara umum komitmen ditandai dengan kepercayaan diri dan hampir tidak ada keragu-raguan diri, suka berbicara pada bidang yang diyakini.

Keempat, identification with significant others, yaitu usaha mengidentifikasikan dirinya terhadap orang yang telah bekerja di bidang yang dipilih atas dasar minat dirinya, misalnya berkenalan, berbicara, dan berdiskusi dengan pegawai jika pilihannya adalah pegawai. Bagi pegawai yang penting adalah figur langsung dan mempunyai konsekuensi langsung bagi pengambilan keputusannya. Pegawai yang punya identitas lebih mampu membedakan aspek-aspek positif dan negatif (yang ia tolak). Kelima, Projecting one's personal future, yaitu pegawai yang mempunyai arah yang semakin jelas tentang masa depannya berkaitan dengan pekerjaan yang telah ia pilih. Komitmen pada suatu bidang tertentu akan menghasilkan perilaku yang konsisten dengan bidang itu dan akumulasi perilaku tersebut akan menghasilkan ide-ide yang jelas tentang masa depannya. Pegawai yang tidak punya komitmen akan cenderung memiliki pengalaman yang terpotong-potong dan tersebar tanpa arah yang jelas. Keenam. Resistance to being swayed, yaitu mencoba bertahan pada pekerjaan yang telah dipilih atau tidak berganti pilihan walau pun ada informasi-informasi negatif tentang pekerjaan yang dipilih atau ada bidang lain yang lebih menarik, misalnya seseorang tetap memilih profesi pegawai walaupun ada informasi bahwa lulusan ilmu kependidikan juga banyak yang menganggur atau pun ada yang mengajaknya menjadi seorang aktor. Respon terhadap godaan dari identitas yang lebih tinggi ditandai oleh tiga aspek yaitu (a) pengakuan akan adanya kemungkinan berubah (b) dapat menghubungkan antara kemungkinan berubah dengan kemampuan dirinya dan kesempatan yang ada di masyarakat, (c) keraguan untuk terlalu mudah berubah kecuali dalam tekanan lingkungan yang jelas.

Jason A. Colquitt, Jeferi A. Lepine, dan Michael J. Wesson (2009:68-69), mengutip pendapat J. P. Meyer, N. J. Allen, dan C. A. Smith menjelaskan tiga bentuk komitmen organisasi sebagai berikut: These sorts of emosional reasons create affective commitment, defined as a desire to remain a member of an organization due an emotional attachment to and involvement whit, that organization. These sorts of emosional reasons create continuance commitment, defined as desire to remain a member of and organization because of an awareness of the costs associated with leaving it. And these sort of reasons create normative commitment defined as a desir to remain a member of an organization due to a feeling of obligation.

Secara ringkas tiga bentuk komitmen organisasi menurut Meyer dan Alen dapat diperjelas melalui gambar di bawah ini :

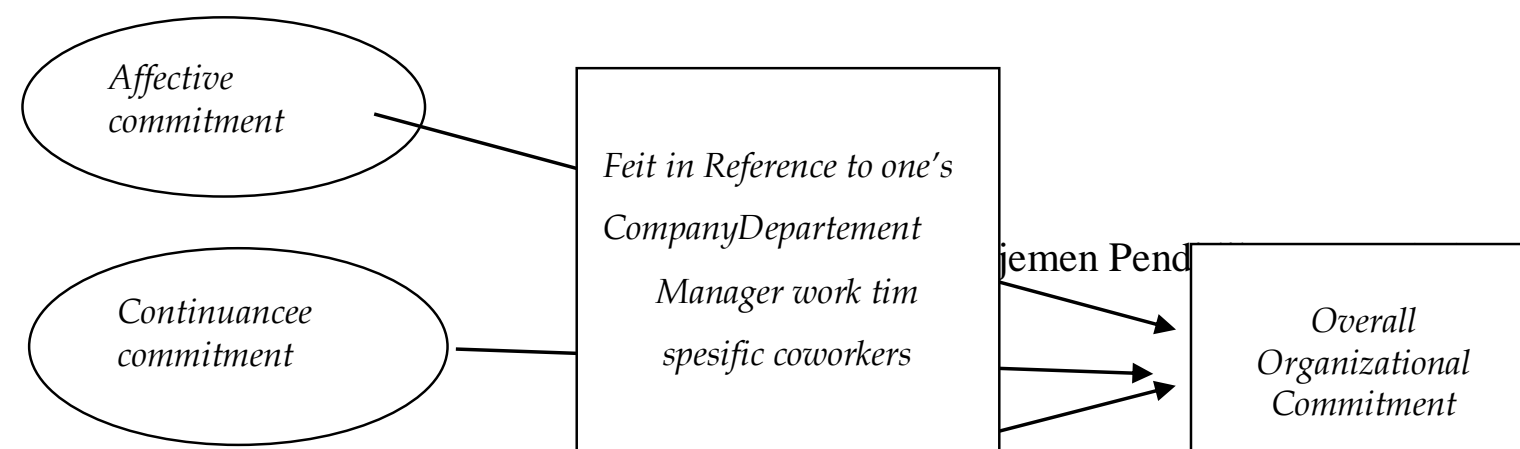


Gambar 1. Driver of Overal Organizational Commitment

Sumber : Jason A. Colquitt, Jeffery A. Lepine, Michael J. Wesson, Organizational Behavior; Improving Performance and Commitment in the Workplace (New York: McGrawHill Irwin,2009), p.97.

Dari uraian konsep dan definisi para ahli penulis menyimpulkan bahwa komitmen organisasi adalah derajat keberpihakan seorang pegawai tehadap organisasinya untuk mencapai tujuan organisasi yang ditandai dengan adanya sikap ingin tetap berada di organisasi (afeksi), keyakinan terhadap organisasi (continuans), dan memberikan loyalitas kepada organisasi (normatif).

\section{Motivasi Berprestasi.}

Motivasi menurut Don Hellriegel dan John W. Slocum, Jr. dalam Hamzah (2007:5) adalah proses psikologis yang dapat menjelaskan perilaku seseorang. Sedangkan perilaku seseorang dirancang untuk mencapai tujuan. Untuk mencapai tujuan tersebut diperlukan proses interaksi dari beberapa unsur. Proses interaksi ini disebut sebagai motivasi dasar yang modelnya dapat digambarkan sebagai berikut:
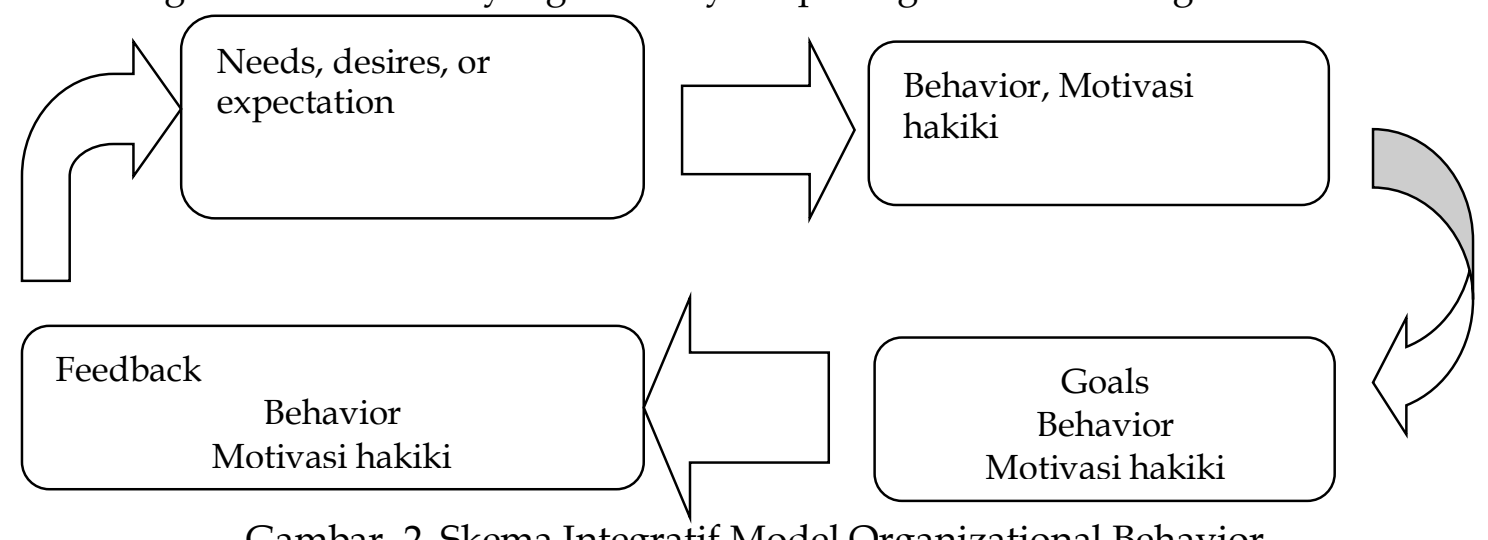

Gambar 2. Skema Integratif Model Organizational Behavior

Sumber: Hamzah B. Uno, Teori Motivasi dan Pengukurannya: Analisis Bidang Pendidikan

(Jakarta: Bumi Aksara,2007), p.5.

Motivasi sebagai sebuah proses juga didefinisikan T. R. Michell sebagaimana yang dikutip Stephen P. Robbin (2009:238), yaitu, motivation as the procesess that account for individual's intensity, direction, and persistence of effort to ward attaining a goal. Motivasi berprestasi, dapat diartikan sebagai dorongan untuk mengerjakan sesuatu tugas dengan sebaik-baiknya berdasarkan standar keunggulan. Motivasi berprestasi mengacu pada 
ukuran keberhasilan berdasarkan tugas-tugas yang dikerjakan seseorang (McClelland:1997:391). Sejalan dengan paparan di atas, Newstrom dan Davis dalam Usman (2006:226) memberikan pola motivasi dengan asumsi bahwa setiap manusia cenderung mengembangkan pola motivasi tetentu sebagai hasil berintraksi dengan lingkungan tempat manusia hidup. Empat pola motivasi yang sangat penting adalah prestasi, afiliasi, kompetensi, dan kekuasaan seperti dijelaskan oleh tabel berikut ini:

Tabel 1. Pola Motivasi Newstrom dan Davis

\begin{tabular}{|l|l|}
\hline \multicolumn{1}{|c|}{ Pola Motivasi } & \multicolumn{1}{c|}{ Keterangan } \\
\hline Prestasi & $\begin{array}{l}\text { Dorongan untuk mengatasi tantangan, untuk maju, untuk } \\
\text { berkembang, untuk mendapatkan yang terbaik, menuju pada } \\
\text { kesempurnan) }\end{array}$ \\
\hline Afiliasi & $\begin{array}{l}\text { Dorongan untuk beruhubungan dengan orang lain secara atas } \\
\text { dasar efektif atas dasar sosial, dorongan untuk memeliliki } \\
\text { sahabat sebanyak-banyaknya. }\end{array}$ \\
\hline Kompetensi & $\begin{array}{l}\text { Dorongan untuk mencapai kerja dengan dengan kualitas tinggi } \\
\text { dan dorongan untuk mencapai keunggulan kerja, } \\
\text { keterampilan memecahkan masalah, dan berusaha keras } \\
\text { berinovasi, tidak mau kalah dengan hasil orang lain. }\end{array}$ \\
\hline Kekuasaan & Dorongan untuk mempengarui orang dan situasi \\
\hline
\end{tabular}

Konsep motivasi berprestasi McClelland juga berhubungan dengan teori motivasi Herzberg. Oleh Accel-Team (1999:4-5) hubungan tersebut digambarkan sebagai berikut : People with high achievement motivation tend to be interested in the motivators (the job it elfs), (2) Achievement motivated people want feedback they want to know how well they are doing on their job, (3) on the other hand, people with low achievement motivation are more concerned about the environment. They want to know how peopel feel about them rather than how well they are doing. Berkenaan dengan motivasi berprestasi, Fred Luthan (2005:274) mendefinisikan prestasi sebagai tingkat di mana orang berharap menyelesaikan sasaran yang menantang, berhasil dalam suatu persaingan, dan menunjukkan keinginan untuk umpan balik yang jelas berkaitan dengan kerja. Individu dengan kebutuhan berprestasi tinggi mempunyai skor tinggi dalam elemen-elemen tersebut. Dari uraian konsep, definisi, dan teori di atas penulis menyimpulkan bahwa motivasi berprestasi adalah dorongan dalam diri seseorang untuk mengatasi segala tantangan dalam pelaksanaan tugasnya untuk mencapai standar pencapaian sasaran yang ditetapkan.

\section{Kepuasan Kerja.}

Pengertian kepuasan kerja didefinisikan oleh banyak penulis. Salah satunya

dikemukakan oleh pakar manajemen organisasi, Fred Luthan (2002:126) yang menyatakan bahwa, "Job satisfaction is a resultof employees" perception of how well their job provides those things which are viewed as important. Pengertian ini memberi arti bahwa kepuasan kerja merupakan persepsi dari seseorang terhadap segala sesuatu yang dilihat penting. Dari pengertian tersebut pada kondisi yang sama seseorang dengan orang lain memiliki tingkat kepuasaan yang berbeda, tergantung dari persepsi masing-masing. 
Berkaitan dengan pengertian tersebut, Steers (1996:389) merangkum pengertian kepuasan kerja dari dua pendapat yang berbeda sebagai berikut: locke (1976) defines job satisfaction as "a pleasurable or positive emotional state [affect] resulting from the appraisal [cognition] of one's job or job experiences." Similarly, Smith, Kendall, and Hulin (1969) regard, "Job satisfactions" as "Feelings or affective responses to face's of the situation, "but in the next sentence "hypothesize that these feelings are assosiated with a perceived difference between what is expected as a fair return. Pengertian tersebut memberi gambaran bahwa kepuasan kerja lebih banyak berkaitan dengan emosi positif yang merupakan hasil dari suatu penilaian secara kognitif dari pekerjaan atau pengalaman. Perbedaan tingkat kognitif oleh orang yang berbeda akan memberikan pengaruh dalam mencapai tingkat kepuasan kerja. Kepuasan juga dikaitkan dengan harapan, jika kenyataan yang diperoleh berbeda dengan harapan maka akan menimbulkan ketidakpuasan. Namun apa pun keadaannya, jika kondisi atau situasi yang ada sesuai dengan harapan maka akan membuat tingkat kepuasan yang tinggi. Aspek-aspek yang biasa muncul dari kepuasan kerja digambarkan secara baik oleh Paul E. Spector (1997:8) pada tabel di bawah ini :

Tabel 2. Aspek-aspek Kepuasan Kerja

\begin{tabular}{|l|l|}
\hline Aspek & Deskripsi \\
\hline Upah & Kepuasan gaji dan kenaikan gaji \\
\hline Promosi & Kepuasan dengan peningkatan karier \\
\hline Supervisi & Kepuasan terhadap pengawas \\
\hline Kompensasi & Kepuasan dengan kompensasi yang didapat \\
\hline Imbalan & Kepuasan dengan perhargaan yang didapat karena prestasi \\
\hline Kondisi kerja & Kepuasan terhadap peraturan dan prosedur \\
\hline Teman sekerja & Kepuasan terhadap teman sekerja \\
\hline Iklim kerja & Kepuasan jenis pekerjaan \\
\hline Komunikasi & Kepuasan \\
\hline
\end{tabular}

Tinggi rendahnya kepuasan kerja berkaitan aspek-aspek di atas sangat tergantung pada sejumlah faktor, antara lain seberapa besar kebutuhan, keinginan, dan harapan seseorang dapat dipenuhi melalui pekerjaan yang dilakukannya. Namun demikian, hal yang berkaitan dengan kebutuhan, keinginan, dan harapan sangat bersifat individual, artinya kebutuhan, keinginan, dan harapan masing-masing orang berbedabeda baik jenis, derajat, maupun jumlahnya sesuai dengan sistem nilai yang dimiliki oleh individu tersebut. Berkaitan dengan tingkat kepuasan Ivancevich (1989:239) mengatakan bahwa, "Job satisfaction depend on the levels of intrinsic and extrinsic outcomes have different values for different people. Dengan demikian tingkat kepuasan berbeda antara satu orang dengan orang lainnya tergantung kepada sikap dan nilai yang dianutnya masing-masing.

Secara ringkas Cornell, Erbert, dan Hatfield (1995-211-212) menjelaskan secara baik pengaruh motivasi berprestasi atau dorongan berprestasi terhadap kepuasan pada gambar di bawah ini : 


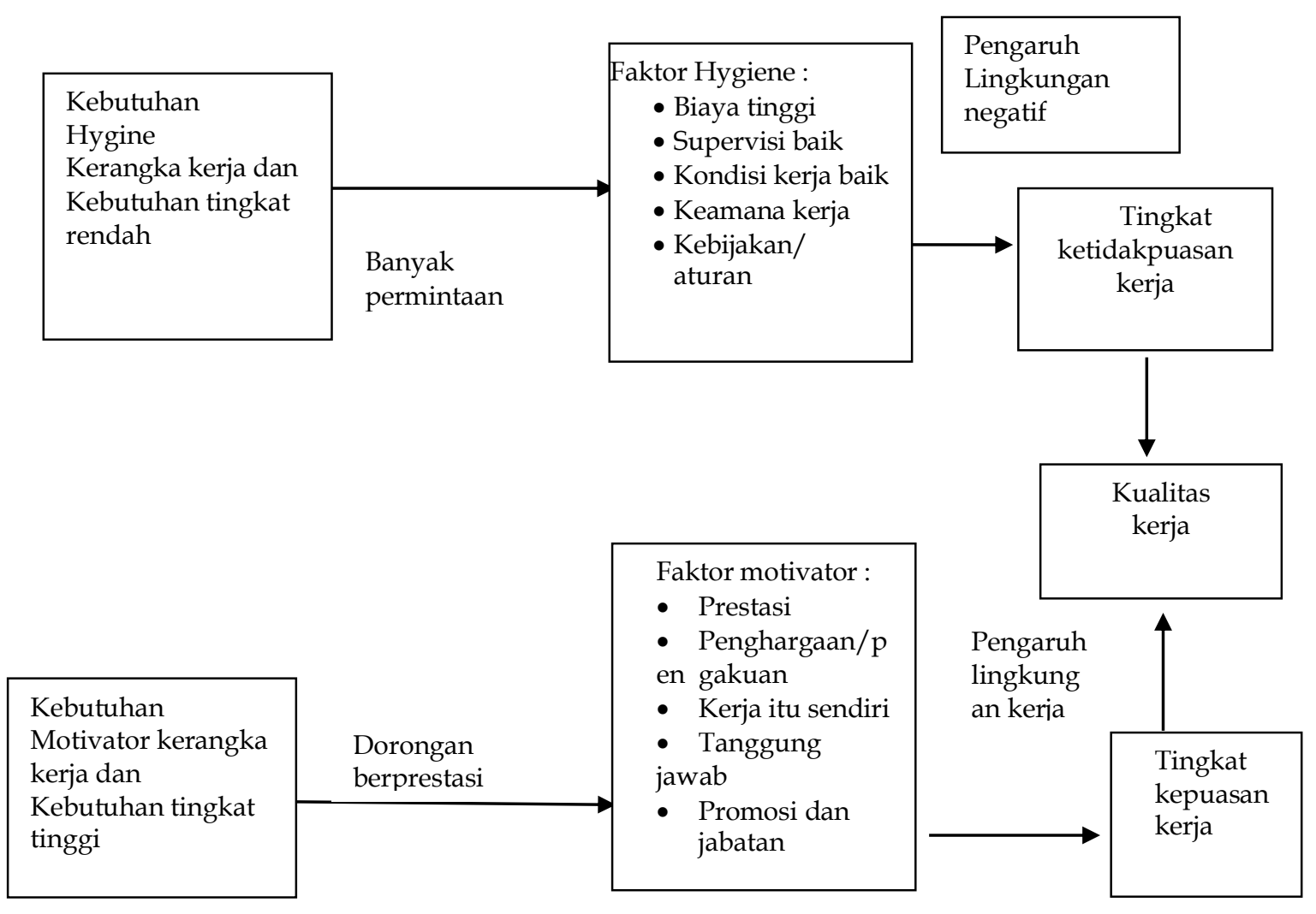

Gambar: 3

Faktor-faktor yang berpengaruh terhadap kepuasan kerja

Sumber : Michael R. Carrell, Norberg, F. Elberg, and Robert D. Hatfield, Human

Resources Management: Global Strategy for Managing a Diverse Workforce (New Jerse:

Prentice-Hall, Inc., 1995), pp.211-212.

Dari gambar terlihat bahwa motivasi adalah kebutuhan yang melahirkan dorongan berprestasi pada pelaksanaan tugas. Dorongan prestasi dan kondusifnya lingkungan kerja akan memberi pengaruh pada kepuasaan kerja seorang pegawai. Berdasarkan hasil penelitian Bavendam Research Incorporated (2005:1), bahwa karyawan yang memiliki tingkat kepuasan kerja tinggi biasanya dicirikan oleh lima hal, yaitu : (1) Percaya bahwa perusahan akan dapat menjaminnya dalam jangka panjang; (2) selalu menjaga kualitas kerjanya; (3) Komitmen pada organisasi; (4) Memiliki ingatan yang tinggi; dan (5) Lebih produktif. Kelima hal tersebut sangat dipengaruhi oleh faktorfaktor seperti peluang dan kesempatan karier, tekanan atau stres, manajemen dan kepemimpinan, standar kerja yang ditetapkan, imbalan yang adil, lingkungan kerja yang kondusif, dan otoritas. Beberapa faktor di atas dapat dilakukan melalui beberapa usaha seperti, Pertama, menentukan visi organisasi yang jelas dan mengakomodasi nilai-nilai yang diyakini karyawan terakses di dalamnya. Kedua, mengikutsertakan karyawan dalam pengambilan keputusan sehingga mereka merasa turut terlibat. Ketiga, organisasi memberikan bimbingan, masukan, dan pedoman untuk meningkatkan profesionalitas dan rasa kebanggaan pada organisasi. Ke-empat, adanya pengakuan dan penghargaan terhadap prestasi karyawan dengan insentif yang memadai sehingga membuat mereka merasa diperhatikan oleh organisasi.

Dari acuan teoretis di atas, secara singkat dapat disimpulkan bahwa kepuasaan kerja merupakan ungkapan perasaan (ekspresi) seseorang (pegawai) terhadap kondisi 
kerja, hasil kerja, dan kerja itu sendiri (work it self) yang menimbulkan rasa senang, rasa puas, rasa bangga yang ditandai dengan indikator-indikator seperti penghargaan akademis, kesempatan berkembang, gaji/imbalan, keakraban dan kerja sama di kampus, fasilitas kerja, kondisi kerja, pengawasan dan kebijakan pimpinan, dan rasa memiliki.

\section{METODE}

Penelitian ini menggunakan metode survey dengan pendekatan kausal. Tempat penelitian dilaksanakan di kampus Universitas Muhammadiyah Sukabumi (UMMI) Jalan R. Samsudin, S.H. No. Kota Sukabumi. Penelitian dilakukan selama 3 (tiga) bulan yaitu pada bulan Mei s.d. Juli 2010. Unit analisisnya adalah dosen tetap dan dosen tidak tetap yayasan sebanyak 59 responden.

\section{HASIL DAN PEMBAHASAN}

Hasil penelitian menunjukkan bahwa komitmen organisasi tidak hanya dipengaruhi oleh unsur motivasi berprestasi saja namun juga dipengaruhi oleh faktor lain yakni kepuasan kerja. Sedangkan faktor kepuasan kerja selain menjadi faktor pengaruh terhadap komitmen organisasi, kepuasan juga menjadi faktor yang dipengaruhi oleh motivasi berprestasi. Sebagaimana disampaikan oleh Luthan (2005: 274) bahwa orang dengan tingkat prestasi/pencapaian tinggi (high achiever) menganggap penyelesaian tugas merupakan hal yang menyenangkan secara pribadi dan rasa senang adalah ungkapan atau ekspresi kepuasan. Hasil dari penelitian ini menunjukkan bahwa terdapat dua variabel yang mempengaruhi komitmen organisasi dan satu variabel yang mempengaruhi kepuasan kerja. Ketiganya menunjukkan pengaruh langsung. Sejalan dengan pendapat Meyer dan Allen (1997), yang lebih memilih untuk menggunakan istilah komponen (dimensi) komitmen organisasi dari pada tipe komitmen organisasi karena hubungan pegawai dengan organisasinya dapat bervariasi dalam ketiga komponen tersebut dan dapat dipengaruhi oleh faktor lain. Temuan penelitian di Universitas Muhammadiyah Kota Sukabumi bahwa motivasi berprestasi dan kepuasan kerja di kalangan dosen dapat digunakan dalam meningkatkan komitmen organisasi, sedangkan faktor motivasi berprestasi di kalangan dosen perlu mendapat perhatian serius karena faktor ini di sisi lain dapat memberikan pengaruh kepuasan kerja bagi dosen ketika dosen yang termotivasi tersebut mampu menyelesaikan tantangan kerja. Hal tersebut berarti bahwa dalam penelitian ini juga menempatkan motivasi berprestasi sebagai alat utama dalam meningkatkan komitmen organisasi dosen. Masing-masing pengaruh antara variabel satu dengan variabel lain dapat diuraikan sebagai berikut:

Pertama, hasil penelitian menunjukkan bahwa motivasi berprestasi berpengaruh langsung terhadap komitmen organisasi dengan koefisien korelasi sebesar 0,631 dengan pengaruh jalur 0,543. Sebagaimana teori Cornell, Erbert, dan Hatfield (1995: 211) pada kebutuhan intrinsik merefleksikan kerangka kerja dengan kebutuhan tingkat tinggi terhadap pelaksanaan pekerjaan. Kebutuhan tersebut meningkatkan dorongan (semangat) berprestasi yang tinggi terhadap penyelesaian tugas dan tantangan keberhasilannya. Sedangkan dorongan untuk berprestasi itulah yang memotivasi seseorang untuk terus tetap bertahan dalam menyelesaikan pekerjaannya dalam organisasi. Kedua, hasil penelitian menunjukkan bahwa kepuasan kerja berpengaruh langsung terhadap komitmen organisasi dengan besar koefisien korelasi 0,512 dengan koefisisen jalur 0,398 sebagaimana teori Bavendam Research Incorporated, (2005:1) bahwa karyawan yang memiliki tingkat kepuasan kerja tinggi biasanya 
dicirikan oleh Komitmen pada organisasi. Ketiga, hasil penelitian menunjukkan bahwa motivasi berprestasi berpengaruh langsung terhadap kepuasan kerja dengan koefisien korelasi 0,407 dengan koefisisen jalur 0.407, sebagaimana teori Cornell, Erbert, dan Hatfield (1995:212) menjelaskan secara baik bahwa motivasi berprestasi atau dorongan berprestasi berpengaruh terhadap kepuasan kerja seorang pegawai.

\section{PENUTUP}

Kesimpulan. Pertama, pengaruh langsung motivasi berprestasi terhadap komitmen organisasi adalah sangat signifikan. Hal ini berarti bahwa semakin kuat motivasi berprestasi dosen maka akan semakin tinggi tingkat komitmen organisasinya. Kedua, pengaruh langsung kepuasan kerja terhadap komitmen organisasi adalah sangat signifikan. Hal ini berarti bahwa semakin kuat tingkat kepuasan kerja dosen maka akan semakin tinggi pula tingkat komitmen organisasinya. Ketiga, pengaruh langsung motivasi berprestasi terhadap kepuasan kerja dosen adalah sangat signifikan. Hal ini berarti bahwa semakin kuat motivasi berprestasi dosen maka akan semakin tinggi pula tingkat kepuasan kerjanya.

Saran. Diperlukan program akademi yang dapat mendorong dosen agar meningkatkan pengetahuan dan keterampilan profesinya, memberi dukungan positif bagi dosen untuk mengembangkan karier dan strata akademisnya, baik atas inisiatif sendiri maupun prakarsa dari pihak kelembagaan yang terkait, Menerapkan sistem kompetisi sehat terutama dalam hal pengembangan karier pegawai. Mengatur sistem pemberian insentif atau konvensasi bagi pegawai yang transparan sesuai dengan tugas dan tanggung jawabnya dalam pekerjaan. Frekuensi pemberian penghargaan baik material maupun non-material kepada dosen yang berprestasi agar ditingkatkan baik secara individu maupun secara kelompok.

\section{DAFTAR RUJUKAN}

Abbas, Syahrizal. Manajemen Perguruan Tinggi. Jakarta : Prenada Media Grup, 2008.

Accel Team, Motivational Theory David Mc Clelland., 1999. Pp.4-5 (http:/www. aceel timecom/maslow/od hr o7. Htm.on-line

Bavendam Research Incorporated, Managing Job Satisfaction. http://www.employee satisfaction.com/2005.

Carrell, Michael R. Norberg, F. Elberg, and Robert D. Hatfield, Human Resources Management: Global Strategy for Managing a Diverse Workforce. New Jerse: PrenticeHall, Inc., 1995.

Colquitt, Jason A., Jeffery A. Lepine, and Michael J. Wesson, Organizational Behavior; Improving Performance and Commitment in the Workplace. New York: McGraw-Hill Irwin, 2009.

Hersey, Paul Kenneth H. Blancard, dan Dewey E. Johnson, Management of Organization Behavior: Utilizing Human Resourcess. New Jersey: Prentice -Hall, Inc, 1996.

Ivancevich, John. et. al., Management Principles and Funtions. Boston: BPI., Irwin, 1989),

J.E., Marcia, et.al. Ego Identity, A. Handbook for Psycological Research. New York: Springer Verlag, 1993. 
Luthan, Fred diterjemahkan oleh Vivin Andika Yuwono, dkk., Perilaku Organisasi Yogyakarta:Penerbit Andi, 2005.

Organization Behavior. Boston: McGraw-Hill Companies, Inc. 2002.

Mc Clelland, David., et. al., Modern Management: Diversity, Quality, Ethics, and the Global Environment. New Jersey: Prentice-Hall International, 1997

Robbin, Stephen P. and Timothy A. Judge, Organizational Behavior. New Jersey : Pearson Education, Inc., Publishing as Prentice Hall, 2009.

Spector, Paul E. Job Satisfaction. USA: SAGE Pub., Inc., 1997.

Steers, Richard M., Lyman W. Porter, and Gregory A. Bigley, Motivation and Leadership at Work. New York: The McGraw-Hill Companies, Inc., 1996.

Uno, Hamzah B., Teori Motivasi dan Pengukurannya: Analisis Bidang Pendidikan. Jakarta: Bumi Aksara, 2007.

Usman, Husaini. Manajemen : Teori, Praktik, dan Riset Pendidikan. Jakarta:Bumi aksara, 2006.

Walker, James W. Human Resource Strategy. Singapore : McGraw-Hill, Inc, 1992. 